\title{
Air-Breathing Microfluidic Formic Acid Fuel Cell with Porous Planar Anode: Experimental and Numerical Investigations
}

\author{
Seyed Ali Mousavi Shaegh†, Nam-Trung Nguyen $\uparrow \S$, Siew Hwa \\ Chan $\dagger$
}

†School of Mechanical and Aerospace Engineering, Nanyang Technological University, 50 Nanyang Avenue, Singapore, 639798

E-mail: mntnguyen@ntu.edu.sg

\begin{abstract}
This paper reports the fabrication, characterization and numerical simulation of an air-breathing membraneless laminar flow-based fuel cell (LFFC) with carbon-fiber-based paper as anode. The fuel cell uses $1 \mathrm{M}$ formic acid as the fuel. Parameters from experimental results were used to establish a three-dimensional numerical model with COMSOL Multiphysics. The simulation predicts the mass transport and electrochemical reactions of the tested fuel cell using the same geometry and operating conditions. Simulation results predict that the oxygen concentration over air-breathing cathode is almost constant for different flow rates of fuel and electrolyte. In contrast, growth of depletion boundary layer of fuel over anode can be the major reason for low current density and low fuel utilization. At a low flow rate of $10 \mu \mathrm{l} / \mathrm{min}$, simulation results show a severe fuel diffusion to the cathode side, which is the main reason for the degradation of open-circuit potential from $0.78 \mathrm{~V}$ at $500 \mu \mathrm{l} / \mathrm{min}$ to $0.58 \mathrm{~V}$ at $10 \mu \mathrm{l} / \mathrm{min}$ as observed in experiments. Decreasing the total flow rate fifty times from $500 \mu \mathrm{l} / \mathrm{min}$ to $10 \mu \mathrm{l} / \mathrm{min}$ only reduces the maximum power density approximately two times from $7.9 \mathrm{~mW} / \mathrm{cm}^{2}$ to $3.9 \mathrm{~mW} / \mathrm{cm}^{2}$, while fuel utilization increases from $1.03 \%$ to $38.9 \%$ indicating a higher fuel utilization at low flow rates. Numerical simulation can be used for further optimization, to find a compromise between power density and fuel utilization.
\end{abstract}

$\S$ To whom correspondence should be addressed (mntnguyen@ntu.edu.sg) 


\section{Introduction}

Membranless laminar flow-based fuel cell (LFFC)is an emerging category of micro fuel cells [1]. This fuel cell concept utilizes the effect of stable liquid interface in co-laminar flows at microscale. Since a LFFC uses a liquid-liquid interface to separate fuel and oxidant, some membrane-related problems such as flooding and dry-out are eliminated. However, proper selection of flow channel design and flow rate are required to avoid issues related to the dynamic liquid-liquid interface such diffusion mixing of the reactive streams.

Low oxygen solubility in aqueous media is a major reason for the low performance of LFFCs [2]. To address this issue, some solutions were utilized with high concentration and high solubility of oxidants such as hydrogen peroxide [3], or vanadium redox couples [4]. Air-breathing capability would allow the practical use of micro fuel cells and their entry into the commercial market. Air-breathing LFFC with an integrated air-breathing gas diffusion cathode $[5,6,7]$ would further simplify the device design and avoid the need of an external reservoir for oxidant solution. These LFFCs benefit from the high concentration of oxygen in air of $10 \mathrm{mM}$ and the higher diffusion coefficient of oxygen in air of $0.2 \mathrm{~cm}^{2} / \mathrm{s}$ compared to the respective values in aqueous media of $2-4 \mathrm{mM}$ and $2 \times 10^{-5} \mathrm{~cm}^{2} / \mathrm{s}[5]$.

In air-breathing LFFC, instead of oxidant stream a stream of electrolyte is used to form the fuel-electrolyte interface and separate the fuel stream from the cathode side, Figure 1. On the one hand, diffusive mixing between fuel and electrolyte reduces he fuel utilization in a single pass and degrades the performance due to the lower concentration of fuel at the vicinity of anode. On the other hand, diffusive mixing leads to fuel crossover and mixed potential at the cathode. Therefore, controlling the dynamic fuel-electrolyte interface is a major design consideration and the main objective for the optimization of a LFFC.

In order to decrease fuel crossover, Hollinger et al. [8] implemented a thin nanoporous separator (polycarbonate with $0.05 \mu \mathrm{m}$ pore size and a pore density of $6 \times 10^{8}$ pores $\mathrm{cm}^{-2}$ ) at the fuel-electrolyte interface which reduces the liquid-liquid contact between the two streams by $98.8 \%$. Applying this method and using a thin layer of Nafion over the cathode to decrease the fuel diffusion to the catalyst layer, the peak power density is increased by a factor of 2.5 from $28 \mathrm{~mW} / \mathrm{cm}^{2}$ to $40 \mathrm{~mW} / \mathrm{cm}^{2}$ at $80{ }^{\circ} \mathrm{C}$.

Tominaka et al. [9] reported a micro direct methanol fuel cell with integrated airbreathing cathode. The whole cell, which is a channel with an open top, was fabricated in silicon as a monolithic structure that omits the electrolyte stream to separate fuel stream from the cathode. Palladium-cobalt ( $\mathrm{Pd}-\mathrm{Co})$ alloy electro-deposited on a thin layer of gold works as the current collector. With sulfuric acid $\left(\mathrm{H}_{2} \mathrm{SO}_{4}\right)$ as the supportive electrolyte, the open-circuit voltage and the maximum power reach $0.5 \mathrm{~V}$ and $1.4 \mu \mathrm{W}$, respectively.

One strategy for further miniaturization and to achieve a more practical design for 
commercialization is the elimination of electrolyte stream. Whipple et al. [7] developed a fuel-tolerant catalyst for the oxygen electro-reduction reactions using rutheniumselenium chalcogenides $\left(\mathrm{Ru}_{x} \mathrm{Se}_{y}\right)$. However, the absolute performance of the cell with $\left(\mathrm{Ru}_{x} \mathrm{Se}_{y}\right)$ is lower than the cell with platinum $(\mathrm{Pt})$ cathode by a factor of $4\left(4 \mathrm{~mW} / \mathrm{cm}^{2}\right.$ versus $\left.16 \mathrm{~mW} / \mathrm{cm}^{2}\right)$. But with this concept, fuel crossover is not a concern anymore, and the electrolyte can be eliminated as the separating stream. Also, a much higher fuel concentration can be used so that the energy density of the cell can be improved.

To consider different strategies and design considerations for the performance optimization, a quantitative determination of species concentration distribution within the fuel cell is inevitable. Some works on modeling and numerical simulation have been carried out to provide a better understanding of electrochemical reactions and mass transport in conventional LFFCs with aqueous fuel and oxidant streams in a microchannel $[11,12,13,14,15]$. In a recent study, Jayashree et al. [10] predicted the concentration of formic acid in the microchannel of an air-breathing LFFC for a cell potential of $0.3 \mathrm{~V}$. Their simulation was based on a three-dimensional (3D) finite-element-method (FEM) model implemented in Femlab 3.2 from COMSOL. Diffusive mixing and fuel utilization for fuel-to-electrolyte rate ratio of 1:1 and 1:5 was investigated.

In the current study, an air-breathing LFFC with porous anode was fabricated and characterized experimentally for three different flow rates. A 3-D model was established in COMSOL in order to solve the species transport equations with corresponding electrochemical reactions over the anode and the air-breathing cathode. This model provides quantitative explanation for the performance of the fuel cell at different flow rates and different operating conditions. Also, in order to determine the contribution of different polarization losses in current-voltage polarization curve, anodic and cathodic activation polarization losses were calculated and discussed. The good quantitative agreement between the experimental and numerical results in terms of predicted current-voltage curve and fuel utilization indicates that the model can be used as a platform to investigate different flow architectures in various operating conditions for the optimization of the fuel cell.

\section{Fabrication of the fuel cell}

Fig. 1 depicts the schematic of our air-breathing LFFC. The fuel cell is mainly made of two pieces of PMMA which were machined by a $\mathrm{CO}_{2}$ laser. The bottom layer is a 2-mm thick PMMA sheet with engraved micro channel for the fuel stream. The channel width and length are $2 \mathrm{~mm}$ and $5 \mathrm{~cm}$, respectively. The channel height of $0.9 \mathrm{~mm}$ was engraved in the PMMA sheet by precisely adjusting the laser power and scanning speed of the laser machining system (Universal M-300 Laser Platform, Universal Laser Systems Inc., Arizona, USA). A piece of plain Toray carbon paper with a typical thickness of $280 \mu \mathrm{m}$ and porosity of approximately $78 \%$ [18], a width of $2 \mathrm{~mm}$ and a length of $4 \mathrm{~cm}$ was placed at the bottom of the channel to work as the anode. The final active area of the anode 

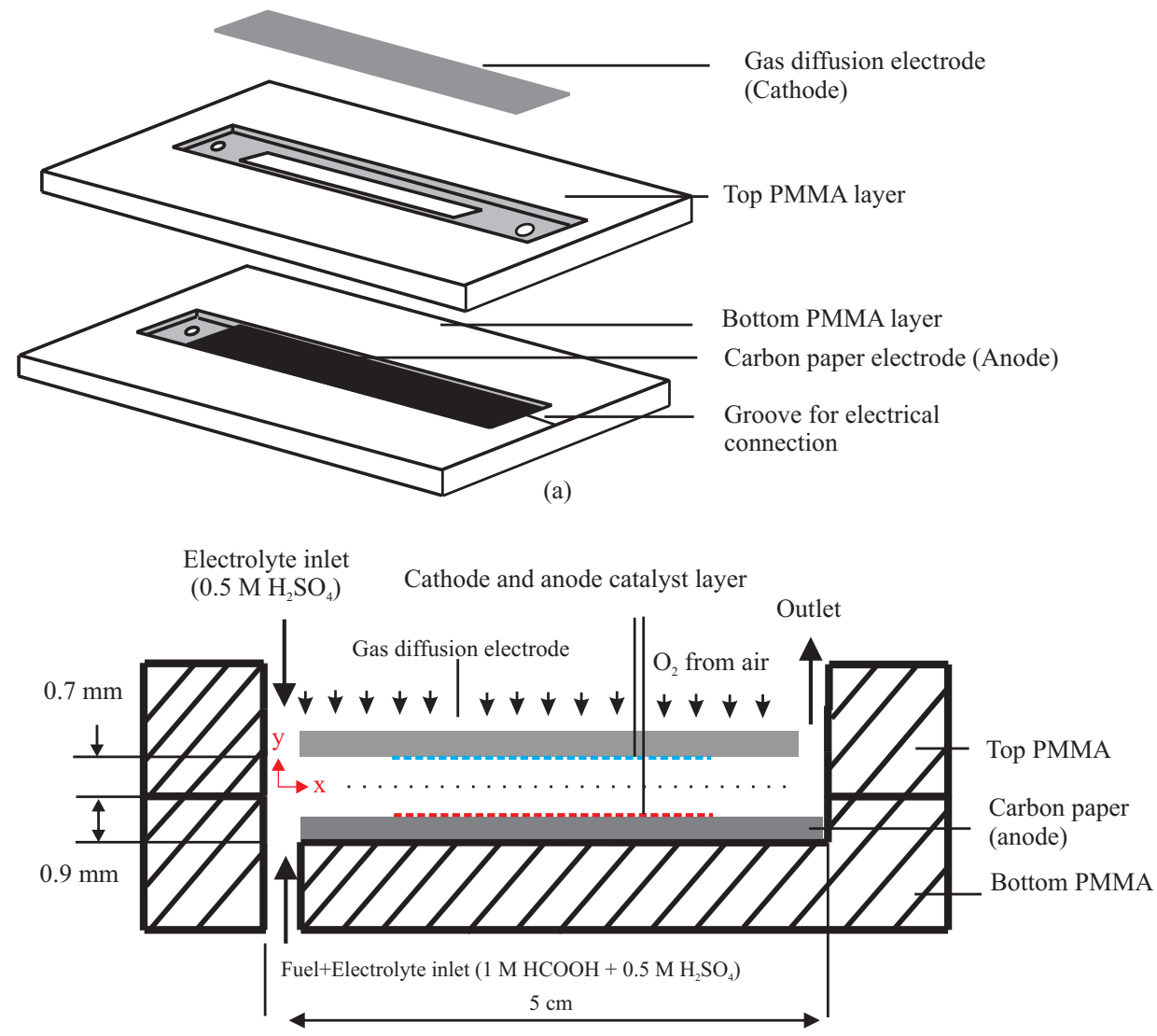

(b)

Figure 1. Schematic of the microfluidic fuel cell: (a) The different layers; (b) Details of fuel cell architecture (not to scale).

measures $2 \mathrm{~mm} \times 3 \mathrm{~cm}$. The active area was coated with platinum ruthenium $(\mathrm{Pt}-\mathrm{Ru})$ alloy nanoparticles working as electrocatalyst. It is to note that the electrooxidation of formic acid on Pt and selected Pt-group metal surfaces is a dual pathway mechanism. Adsorbed carbonate monoxide can be produced at the formic acid dehydration pathway which is a poisoning intermediate and can block the dehydrogenation pathway, which is the direct path for generating active intermediate of $\mathrm{H}^{+}$and releasing electrons $[16,17]$. Since Pt-Ru has a significant increase in the rate of formic acid electrooxidation [16], catalyst ink was prepared using $10 \mathrm{mg} / \mathrm{cm}^{2}$ of $\mathrm{Pt}-\mathrm{Ru}$ 20:20 atom wt\% alloy (E-TEK) and $1.5 \mathrm{mg} / \mathrm{cm}^{2}$ of Nafion (5 wt\% Nafion 5112, DuPont). After extensive ultrasound mixing, the ink was spread on the top surface of the anode to produce the $0.6 \mathrm{~cm}^{2}$ active area for formic acid oxidation.

A 1-mm thick PMMA sheet was cut by the same $\mathrm{CO}_{2}$ laser system to work as the cover for the channel. This PMMA layer has a $2 \mathrm{~mm} \times 3 \mathrm{~cm}$ slot to hold the cathode made of Toray carbon paper. Carbon paper was dipped in a $5 \%$ polytetrafluoroethylene (PTFE) solution for two minutes. After drying in room temperature, the paper was backed at $250^{\circ}$ for 30 minutes and at $350^{\circ}$ for another 30 minutes to prepare a hydrophobic surface. The PTFE coating avoid liquid leakage from the channel through 


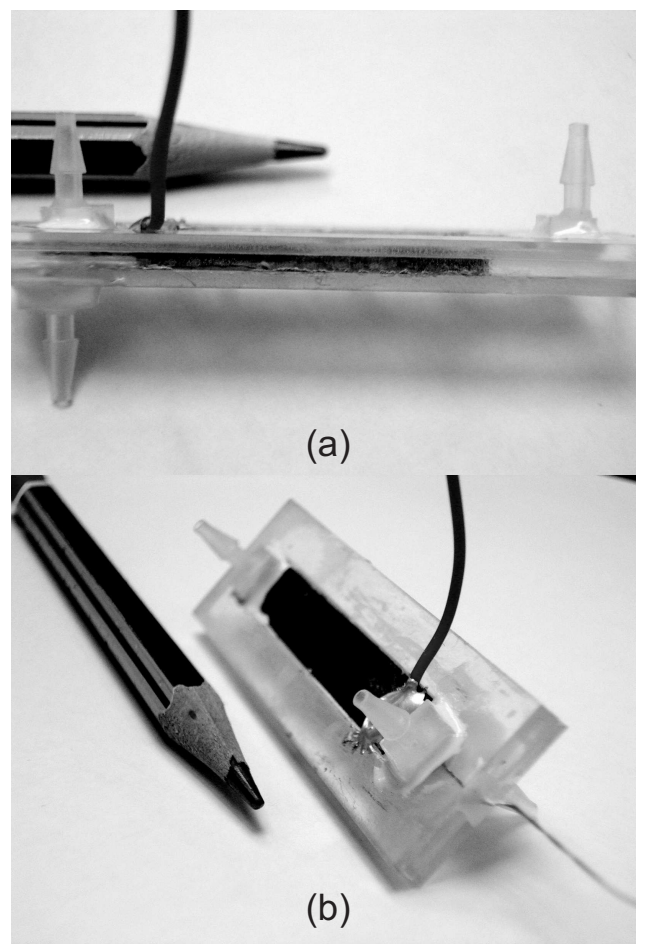

Figure 2. Fabricated fuel cell: (a) Arrangement of inlets and outlet; (b) Gas diffusion electrode and wires attached to anode and cathode.

the porous carbon paper to the environment. It is worthy to note that immersion of carbon paper in PTFE solution decreases its porosity depending on the content of PTFE solution [18]. For 5\% PTFE content, the porosity decrese is less than 1\% [18]. The cathode has a double layer catalyst loading [6]. The first layer contains $0.3 \mathrm{mg} / \mathrm{cm}^{2}$ platinum nanoparticles supported on Vulcan XC 72 (Alfa-Aesar). The second layer, which is exposed directly to the liquid electrolyte (0.5 M Sulfuric Acid), has a loading of $2 \mathrm{mg} / \mathrm{cm}^{2}$ platinum and approximately $0.1 \mathrm{mg} / \mathrm{cm}^{2}$ of Nafion to enhance the proton conductivity. The gas diffusion electrode is assembled on the PMMA sheet using epoxy (Araldite, Huntsmann, USA). Before bonding the two PMMA sheets, both PMMA surfaces are mechanically treated by fine sand papers to improve the surface roughness and better adhesion. The two PMMA pieces were then bonded together using chloroform. Electrically conducting copper wires were attached to the electrodes using conductive silver epoxy (Chemtronics, USA). The electrodes are aligned and positioned to maintain the $0.6 \mathrm{~cm}^{2}$ active surface area on both electrodes. The fuel and electrolyte inlets were cut by the laser system and have a diameter of $1.3 \mathrm{~mm}$. A single outlet with a diameter of $2 \mathrm{~mm}$ was cut on the top layer. Fluidic interconnects were glued to the cell using epoxy adhesive. Tubing with inner diameter of 0.062 inch and outer diameter of 0.125 inch (Cole-Parmer) was used for delivering fuel, electrolyte and the waste. After the final assembly, the LFFC was tested for leakage with de-ionized (DI) water. Fig. 2 depicts the assembled LFFC. 


\section{Characterization of the fuel cell}

Our LFFC is running by a solution of $1 \mathrm{M}$ formic acid with $0.5 \mathrm{M}$ sulfuric acid (supportive electrolyte) as fuel and a stream of $0.5 \mathrm{M}$ sulfuric acid as electrolyte. Formic acid, compared with methanol, has a faster kinetics of electrooxidation at room temperature [20]. Also, formic acid is a strong electrolyte, so it can enhance both electronic and proton transport at the anode side, and also it is common to the environment [21].

The electrolyte stream separates the fuel from direct exposure to cathode. The flow rate of the fuel and the electrolyte streams are kept constant at a fixed ratio of 1:1. The fuel cell was tested with fuel flow rates of 10, 100 and $500 \mu \mathrm{l} / \mathrm{min}$. Both fuel and electrolyte streams were delivered by a syringe pump (KD Scientific). Introducing the electrolyte stream into the channel has two main functions. The first function is to avoid mixed potential due to oxidation of formic acid at the cathode that can dramatically reduce the performance [7]. The second function is preventing catalyst poisoning due to formic acid oxidation at the Pt supported cathode. Both catalyst poisoning and mixed potential on cathode are the consequences of fuel diffusion from anode to cathode across the channel. Fuel diffusion can be minimized by fine adjustment of fuel and electrolyte streams.

The generation of electricity in the LFFC follows the electrochemical reactions at the anode and the cathode. At the anode, formic acid decomposes and creates electrons and protons:

$$
\mathrm{HCOOH} \rightarrow \mathrm{CO}_{2}+2 \mathrm{H}^{+}+2 \mathrm{e}^{-} \quad E_{0}=0.22 \mathrm{~V}
$$

Oxygen diffusing into $\mathrm{H}_{2} \mathrm{SO}_{4}$ solution reacts with electrons from the cathode and protons from the liquid-liquid interface to form water. The catalytic oxygen reduction reaction $(\mathrm{ORR})$ is a multi-electron process with a number of elementary steps, entailing different reaction intermediates [19]. Without considering the reaction intermediates, the oxygen reduction at cathode is considered as:

$$
\mathrm{O}_{2}+4 \mathrm{H}^{+}+4 \mathrm{e}^{-} \rightarrow 2 \mathrm{H}_{2} \mathrm{O} \quad E_{0}=1.229 \mathrm{~V}
$$

The characterization was carried out at room temperature of $25{ }^{\circ} \mathrm{C}$. The current at different cell potentials were measured with an electric load system (Solartron Analytical, Solartron Group Limited, UK). The results were evaluated with MultiStat electrochemistry software (Scribner Associates, Inc. USA). Data were recorded after a

stable condition of flow rate and temperature is reached. Based on the dimension of the flow channel and the flow rates, the residence time of the fuel from the inlet to the outlet of the cell ranges approximately from 10 to 500 seconds. Thus, a potential scanning rate of $5 \mathrm{mV} / \mathrm{sec}$ can provide enough time to capture effects such as diffusive mixing at the interface of the laminar streams. 


\section{Modeling the transport and electrochemical phenomena}

To have quantitative understanding of the the experimental results, a three dimensional model based on a finite-element-method (FEM) software (COMSOL Multiphysics) was established. The model solved the coupled electrochemical reactions and transport phenomena within the fuel cell at the same experimental operating conditions and the same geometry.

\subsection{Hydrodynamic equations}

To solve the flow field in the channel and through the porous anode, Navier-Stokes and continuity equations are solved for the steady state, laminar flow $(\operatorname{Re}<10)$. Isothermal condition inside the channel and negligible body forces are assumed.

$$
\begin{aligned}
& \nabla \cdot(\rho u)=0 \\
& \nabla \cdot(u u)=-\frac{1}{\rho} \nabla p+\nabla \cdot(v \nabla u)
\end{aligned}
$$

where $p$ is the static pressure, $\mathbf{u}$ the velocity vector, $\rho$ the fluid density, and $\nu$ is the kinematic viscosity. The system is considered as an isothermal system, because the viscous dissipation due to the low liquid velocities through the channel $(\mathrm{u}<1 \mathrm{~cm} / \mathrm{s})$ can be neglected [11]. Since the anolyte and electrolyte are dilute solutions, the input density of anolyte and electrolyte are considered as that of water.

To solve the flow distribution in the porous media, Darcy's law is used [22]:

$$
u=-\frac{k}{\mu} \nabla p
$$

where $k$ is the intrinsic permeability of the porous media. Intrinsic permeability, which is known as permeability for the single phase flow, is independent of the nature of the fluid, and dependant on the geometry of the medium [22].

\subsection{Mass transport and electrochemical model}

The electrooxidation of formic acid to carbon dioxide $\mathrm{CO}_{2}$ on a metal surface is accepted to take place via a dual path mechanism, dehydrogenation and dehydration [17]. In the current model, the direct pathway is assumed to be the dominant oxidation of formic acid as indicate in (1). The catalytic oxygen reduction reaction (ORR) is a multi-electron process with a number of elementary steps, entailing different reaction intermediates [?]. Without considering the reaction intermediates, the oxygen reduction at cathode is considered as denoted by (2).

The electrochemical reaction takes place over electrodes. Anode and cathode are both made of porous carbon paper covered by a thin layer of catalyst particles. The catalyst layer is treated as a boundary, where the corresponding electrochemical reactions take place over these boundaries. So the effect of these reactions on the species concentration appears as the source term, $S$ in the equation of conservation of species:

$$
\nabla \cdot\left(-D_{i} \nabla C_{i}+C_{i} \vec{u}\right)=S_{i}
$$


where $S_{i}$ is the net rate of change of species " $i$ " by electrochemical reactions over anode and cathode, and represents the rate of consumed species per cubic meter. $D_{i}$ is the diffusion coefficient of species " $i$ " in the corresponding media, which refers to formic acid in the anode and oxygen in the cathode. So, the value of $D$ for anodic and cathodic reactions are considered as formic acid diffusivity in aqueous media (water) and oxygen diffusivity through gas diffusion electrode (GDE), which is made of carbon paper, and the aqueous media of electrolyte, respectively. $C$ is the concentration of corresponding species in anode and cathode.

The rate of formic acid electrooxidation in anode and electroreduction of oxygen in cathode are given by:

$$
S_{i}=\left(\frac{j_{0}}{n_{i} F}\right)\left(\frac{C_{i}}{C_{i, \mathrm{ref}}}\right)^{\beta_{i}}\left[\exp \left(\frac{\alpha_{a} F \eta}{R T}\right)-\exp \left(-\frac{\alpha_{c} F \eta}{R T}\right)\right]
$$

where $j_{0}$ is the exchange current density at reference reactant concentration $C_{i \text {,ref }}, \beta_{i}$ is the reaction order of species " $i$ " for the elementary charge transfer step. Since the rate determining step is a first-order reaction, $\beta=1$ is chosen [11], $\alpha_{a}$ and $\alpha_{c}$ are the anodic and cathodic charge transfer coefficients, $R$ is the universal constant and $T$ is the operating temperature and considered as a constant parameter, $F$ is the Faraday's constant, and $\eta$ is the activation overpotential.

Oxygen from atmosphere diffuses through the GDE to reach the catalyst layer. To determine the oxygen concentration through the GDE, Equations (6) and (7) are solved with input values and appropriate boundary conditions listed in Tables 1 and 2 .

On the catalytic surface, only the normal flux to the surface contributes to power output of the cell and is given by:

$$
\vec{n} . \nabla \cdot\left(-D_{i j} \nabla C_{i}+C_{i} \vec{u}\right)=S_{i}
$$

Due to the porous structure of cathode and anode, the binary diffusion coefficients utilized in the porous media are corrected for the porosity $(\varepsilon)$ and tortuosity $(\tau)$ of the media as follows [23]:

$$
D_{i j}^{\mathrm{eff}}=D_{i j} \frac{\varepsilon}{\tau}
$$

In addition to proton diffusion to the cathode side, formic acid can diffuse and reach the cathode at low flow rates. Formic acid in adjacent to the cathode catalyst can be oxidized decreasing the cathode voltage due to the mixed potential. In this model the effect of fuel crossover on the cathode is not considered.

\subsection{Boundary conditions}

Fuel-to-electrolyte flow rate ratio of $1: 1$ is chosen while the outlet hydrodynamic boundary condition is set on zero pressure. The software is run for three different flow rates, 500, 100 and $10 \mu \mathrm{l} / \mathrm{min}$ which can be addressed as $Q_{1}, Q_{2}$ and $Q_{3}$ with the corresponding inlet velocity of $0.006,0.0012$ and $0.00012 \mathrm{~m} / \mathrm{s}$, respectively.

To solve the mass transport, constant concentration of formic acid (1 M) is set at the inlet for anolyte stream for all simulations while the concentration of formic acid at 
the inlet of electrolyte stream is set to be zero. Also, the outlet condition is convective mass transport. For the GDE, the upper surface exposed to the ambient air has an inlet concentration equal to the oxygen concentration of atmosphere $\left(0.21 p_{a t m} / R T\right)$ [24], while the bottom surface, working as catalytic surface, has an inward flux of $\mathrm{SO}_{2}$ from Equation (7). At the liquid-liquid interface between two streams, the continuity condition was applied for velocity and species concentration. All used parameters to solve the required equations are listed in Tables 1 and 2, where the values are complied from $[23,24,25,26,27]$.

\subsection{Cathode and anode overpotential}

In order to solve Equation (7), species concentration and activation overpotential must be known for both electrodes. Furthermore, to draw the $I-V$ curve, both voltage and the corresponding cell current density must be considered. To obtain the $I-V$ curve, cell current is fixed and the corresponding voltage is calculated [28] by taking into account of different polarization losses based on the empirical data of the fabricated cell. It is worthy to note that for any fuel cell, the operating potential can be calculated as the departure from ideal voltage caused by the various polarizations [29]:

$$
E_{\text {cell }}=E^{o}(T, P)-\eta_{a, a}-\left|\eta_{a, c}\right|-\eta_{r}-\eta_{m, a}-\left|\eta_{m, c}\right|-\eta_{x}
$$

where $E^{0}(T, P)$ is the theoretical equilibrium open-circuit potential for the cell, calculated from the Nernst equation. $\eta_{a, a}$ and $\eta_{a, c}$ represent the activation overpotentials at the anode and cathode. $\eta_{r}$ is the Ohmic loss and occurs because of the resistance to the flow of electrons through the electrode materials and the electric contacts. The mass transfer (concentration) polarization at anode and cathode are presented as $\eta_{m, a}$ and $\eta_{a, c}$, respectively. Crossover effect of fuel/oxidizer through the electrolyte or internal short circuits in the cell can be presented by $\eta_{x}$ which is responsible for the departure of theoretical equilibrium open-circuit potential from the Nernst equilibrium voltage.

Experimental data in Fig. 3(a) shows that there is no sharp drop of the voltage at high current densities for the given geometry and operation conditions. Therefore, to simplify the modeling, mass transfer overpotential can be neglected. Also effect of mixed potential of the cathode and other parasitic losses can be taken into account in the open-circuit potential which is obtained from experiment. So, Equation (11) can be considered as a semi-empirical equation and simplified to:

$$
E_{\text {cell }}=E_{\mathrm{OCV}}-\eta_{a, a}-\left|\eta_{a, c}\right|-\eta_{r}
$$

where $E_{\mathrm{OCV}}$ is the experimental open circuit voltage obtained from the I-V curve at a given flow rate, Fig. (3a). According to Equation (7) the current density is dependent on the concentration of the fuel and the oxidant. So, the species concentration can be calculated at a fixed current density with corresponding activation overpotentials, $\eta_{a, a}$ and $\eta_{a, c}$ while the flow rate is known.

Figure 3(a) shows that the maximum current density (limiting current) is not determined by mass transfer overpotential, especially for $Q_{1}$ and $Q_{2}$. The only exception 
Table 1. The value of input constants for the simulation.

\begin{tabular}{llll}
\hline Parameter & Description & Values used & Units \\
\hline$C_{0, \mathrm{HCOOH}}$ & Reference concentration of formic acid & 500 & $\mathrm{~mol} / \mathrm{m}^{3}$ \\
$C_{0, \mathrm{O}_{2}}$ & Reference concentration of oxygen & 85 & $\mathrm{~mol} / \mathrm{m}^{3}$ \\
$D_{\mathrm{O}_{2}\left(\mathrm{H}_{2} \mathrm{O}\right)}$ & Diffusivity of oxygen in water & $2.1 \times 10^{-9}$ & $\mathrm{~m}^{2} / \mathrm{s}$ \\
$D_{\mathrm{O}_{2}(\text { air })}$ & Diffusivity of oxygen in air & $2.1 \times 10^{-5}$ & $\mathrm{~m}^{2} / \mathrm{s}$ \\
$D_{\mathrm{HCOOH}}$ & Diffusivity of formic acid as anolyte & $2.546 \times 10^{-9}$ & $\mathrm{~m}^{2} / \mathrm{s}$ \\
$n_{\mathrm{a}}$ & Number of transferred electrons at anode & 2 & - \\
$n_{\mathrm{c}}$ & Number of transferred electrons at cathode & 4 & - \\
$F$ & Faraday's constant & 96485 & $\mathrm{C} / \mathrm{mol}$ \\
$j_{0, \mathrm{a}}$ & Exchange current density at anode & 600 & $\mathrm{~A} / \mathrm{m}^{2}$ \\
$j_{0, \mathrm{c}}$ & Exchange current density at anode & $5 \times 10^{-6}$ & $\mathrm{~A} / \mathrm{m}^{2}$ \\
$k$ & In-plane permeability of carbon paper & $1 \times 10^{-12}$ & $\mathrm{~m}{ }^{2}$ \\
$K$ & Electrical conductivity of electrodes & 300 & $(\Omega . \mathrm{m})^{-1}$ \\
$R$ & Universal gas constant & 8.314 & $\mathrm{~J} / \mathrm{mol} . \mathrm{K}$ \\
$T$ & Temperature & 298 & $\mathrm{~K}$ \\
$\varepsilon$ & Porosity of carbon paper used as GDE and anode & 0.7 & - \\
$\mu$ & Viscosity & $10^{-3}$ & $\mathrm{~kg} / \mathrm{m} . \mathrm{s}$ \\
$\rho$ & Density of anolyte and electrolyte stream & 1000 & $\mathrm{~kg} / \mathrm{m}^{3}$ \\
$\tau$ & Tortuosity of carbon paper & 3 & - \\
\hline
\end{tabular}

is the flow rate of $10 \mu \mathrm{l} / \mathrm{min}$ with a short drop observed at the limiting current. So, the main overpotential losses are mainly associated with activation and Ohmic losses. The Ohmic losses are mainly attributed to the electrolyte proton conductivity and external resistance of electrodes and connections. Ohmic losses of the cell are calculated by:

$$
\eta_{r}=i \cdot\left(R_{\text {electrolyte }}+R_{\text {external }}\right)
$$

where $R_{\text {electrolyte }}$ is caused by the ionic conductivity of the electrolyte. To determine the ionic conductivity across the channel from anode to cathode, $0.5 \mathrm{M}$ sulfuric acid is mixed with $1 \mathrm{M}$ of formic acid. The ionic conductivity of $0.5 \mathrm{M}$ sulfuric acid was measured to be $0.2 \mathrm{~S} / \mathrm{cm}[6]$.

Based on an anode to cathode spacing of $1.4 \mathrm{~mm}$, a solution resistance of $0.7 \Omega . \mathrm{cm}^{2}$ is obtained. Cell potential minus activation and electrolyte losses leaves the losses of external resistance $R_{\text {external }}$. A value of $4.9 \Omega$ is considered for external resistance, obtained from the electrochemical impedance spectroscopy (EIS)of the cell, including the resistance of wiring and the electrical contacts.

To solve Equation (11), $E_{\mathrm{OCV}}$ and $\eta_{r}$ are obtained from the experimental data while the anodic and cathodic activation overpotentials, $\eta_{a, a}$ and $\eta_{a, c}$ are obtained from the simulation. In this case, the voltage calculated using Equation (11) is called $V_{\text {cell,model }}$. 
Table 2. Boundary conditions used for hydrodynamic and electrochemical reactions, reproduced after [10].

Boundary conditions to solve Equations 3 and 4

$\mathbf{u}=\left(0, \mathrm{u}_{0}\right)$ where $\mathrm{u}_{0}$ is the inlet velocity $(0.006,0.0012,0.00012 \mathrm{~m} / \mathrm{s})$

$\mathbf{u}=(0,0)$ at the walls

$p=0$ at the outlet

Boundary conditions to solve Equation 6 for anode and cathode reactions:

$C=C_{0}$ at the inlet of anolyte stream

$C=0$ at the inlet of electrolyte stream

$(-D \nabla C+C \mathbf{u}) \cdot \mathbf{n}=0$ at the non-catalytic walls

$(-D \nabla C) \cdot \mathbf{n}=0$ at the outlet
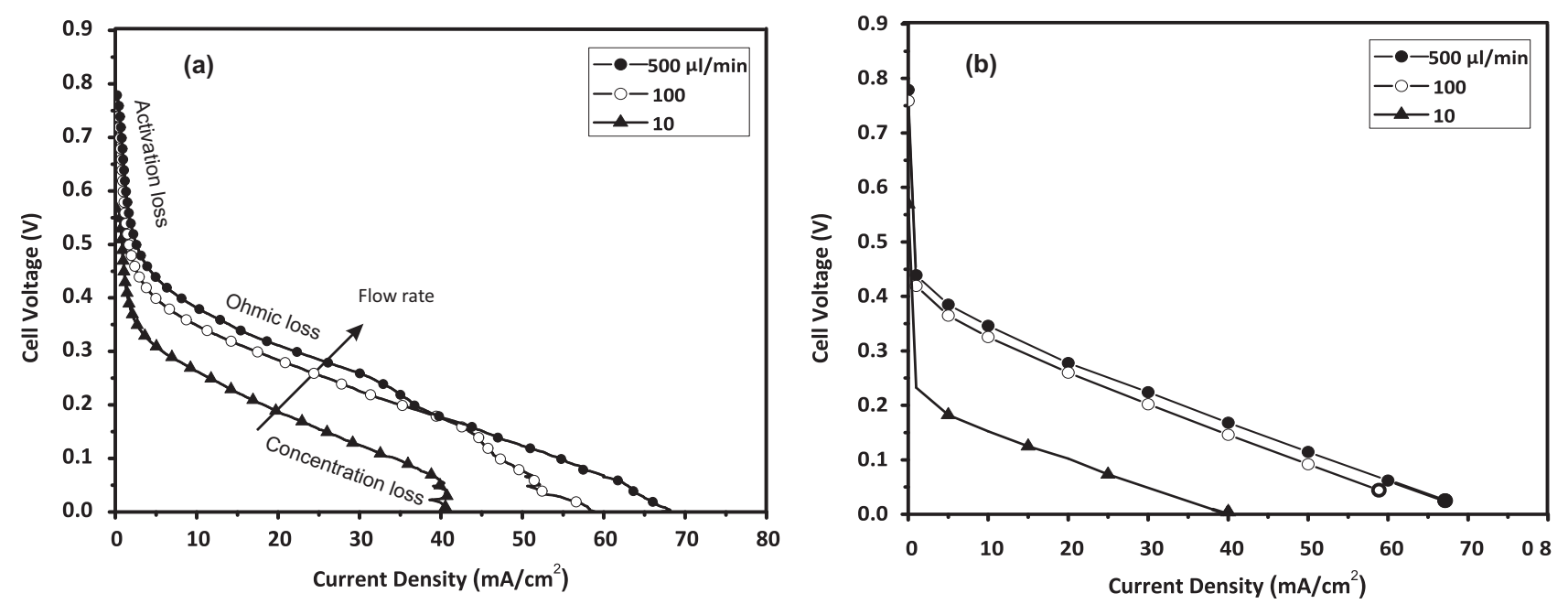

Figure 3. The (a) experimental and (b) simulated polarization curves of the fuel cell running by formic acid. Oxygen is supplied from the atmosphere through a gas diffusion electrode.

\section{Results and discussion}

\subsection{Current-voltage polarization curve}

The cell potential was calculated using Equation (11) at three flow rates of 10, 100 and $500 \mu \mathrm{l} / \mathrm{min}$, Fig. 3(b). For most data points, there is agreement between experimental and numerical results. At high current densities, especially for $10 \mu \mathrm{l} / \mathrm{min}$, the fluctuations are attributed to the generation of carbon dioxide bubbles over the anode due to electrooxidation of formic acid, Fig. 3(a). These bubbles can block the active sites of the anode for a short while, but can be dissolved in the stream or washed away by the stream drag force before growing large enough to block the channel. The difference between the experimental and numerical results mainly arises from the concentration losses which are not taken into account in the simulation.

To have a more quantitative visualization of the contribution of the three polarization losses (activation, ohmic and concentration) in decreasing the cell potential, 


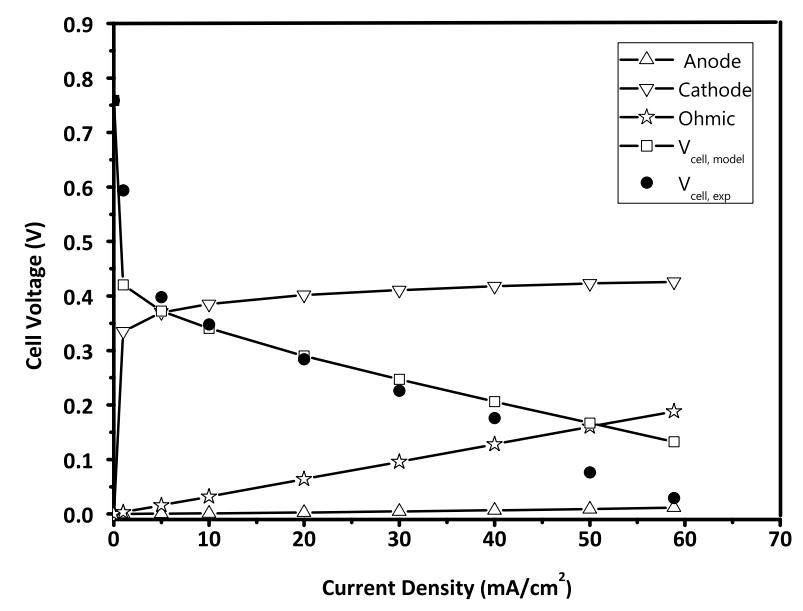

Figure 4. Contribution of different polarization losses.

individual losses were plotted in Fig. 4. Cathodic overpotentioal due to the sluggish electroreduction of oxygen has the largest contribution in voltage drop, especially at low current densities. Anodic loss is negligible compared with cathodic one. Ohmic loss is linear and increases by the growing current density.

\subsection{Concentration distribution of formic acid}

The typical open-circuit voltage of an air-breathing LFFC with similar fuel and electrolyte is in the range of $0.7 \mathrm{~V}$ to $0.9 \mathrm{~V}$ [5]. Since the microfluidic fuel cell takes the advantage of co-laminar streams, changes in flow rate will affect the molecular diffusion and consequently the cell performance.

As Fig. 5 shows, at the highest flow rate $Q_{1}$, due to the high Peclet number of the stream $(P e=850)$, the mixing region is limited to a very thin zone at the middle of the channel, while for $Q_{2}$ and $Q_{3}(P e=170$ and 17), diffusion at the liquid-liquid interface is obvious. At $Q_{3}$, fuel can diffuse across the electrolyte stream and even reach the cathode side.

Catalyst layer over the carbon paper of the anode is inside the channel from $x=$ $1 \mathrm{~cm}$ to $x=4 \mathrm{~cm}$. Fuel consumption over anode produces a depletion boundary layer. At high flow rates the depleted fuel is replenished by the stream rapidly. Decreasing the feeding flow rate leads to the formation of a zone with low fuel concentration. At flow rate of $Q_{3}$, the growth of depletion boundary layer over anode is obvious.

The fuel cell characteristics shown in Fig. 3 clearly shows the three typical regions of activation loss, ohmic loss and concentration loss. Numerical results in Fig. 5 indicate the lower diffusive mixing at high fuel flow rate allows a higher fuel concentration to reach the anode leading to the decrease of concentration loss. At medium current densities, all curves are almost parallel indicating the same ohmic loss, which is determined by the concentration of the electrolyte solution and the conductivity of the electrode and 


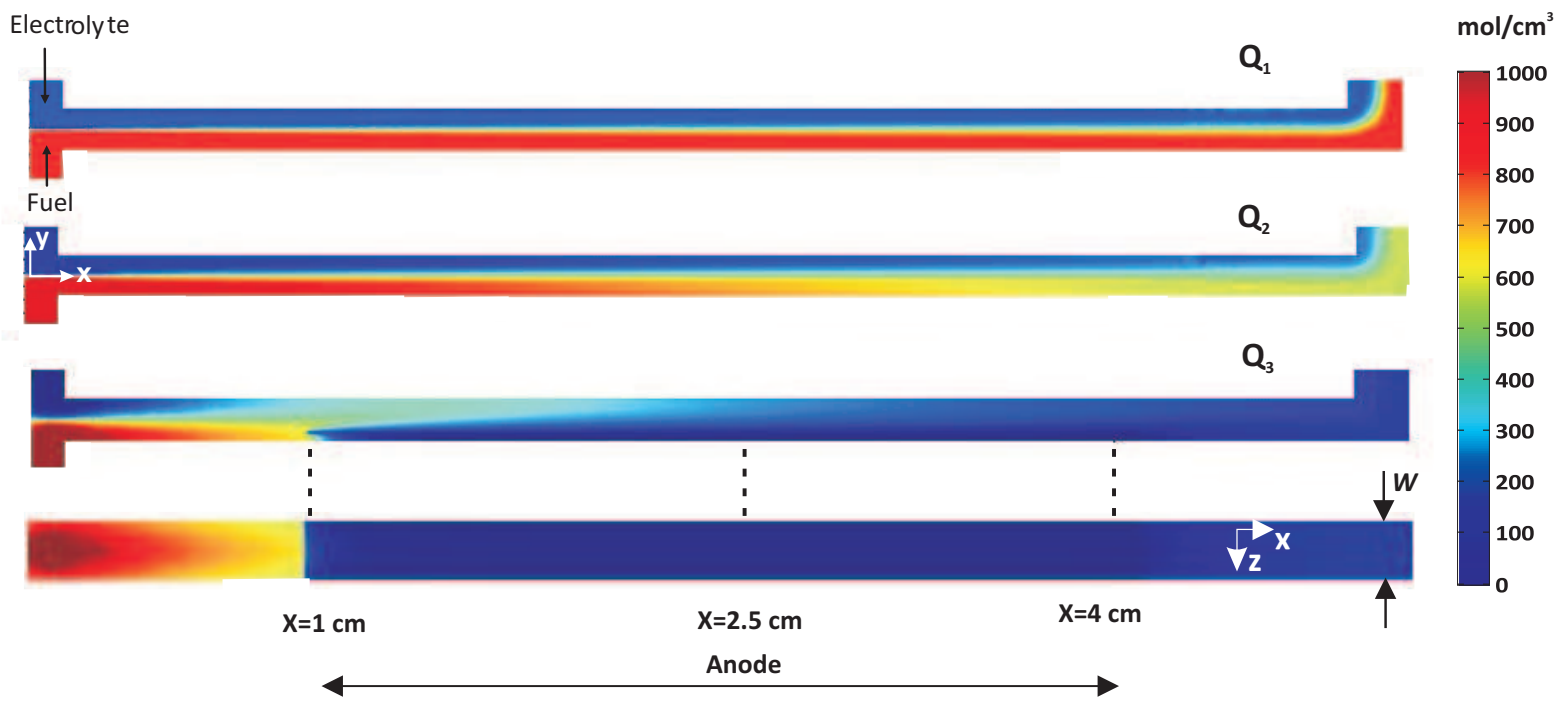

Figure 5. Concentration profiles of formic acid for the three flow rates of $Q_{1}, Q_{2}$, and $Q_{3}$ with inlet concentration of $1000 \mathrm{~mol} / \mathrm{m}^{2}(1 \mathrm{M})$. The T-shaped cross-section of the channel is located at the $x-y$ plane which cut through the center of the channel $z$ $=1 / 2 W)$ with a width of $W$.

electrical interconnects. In the region of concentration loss, the curve of $Q_{3}$ in Fig. 3 shows a higher loss due to the depletion of the fuel as depicted in Fig. 5. At the high fuel flow rate of $500 \mu \mathrm{l} / \mathrm{min}$, the region of concentration loss is almost non-existent.

A more quantitative illustration of numerical results in Fig. 5 as concentration distribution in Fig. 6 obviously reveals that by decreasing the flow rate, the content of formic acid over cathode increases. Decreasing the flow rate increases the residence time of the fuel and the electrolyte in the channel and enhances diffusive mixing at the interface [11]. Fig. 6(a) shows that fuel concentration over cathode at the end of the cathode $(x=4 \mathrm{~cm})$ is almost zero, because the residence time of flow in the channel ( $\sim 10$ second $)$ is so short compared to $Q_{2}$ and $Q_{3}(\sim 50$ and $\sim 500$ seconds $)$. The corresponding values of fuel concentration of $Q_{2}$ and $Q_{3}$ are 120 and $260 \mathrm{~mol} / \mathrm{m}^{3}$. The fuel crossover is significant at lower flow rates and has two consequences. First, the concentration of fuel in the anolyte stream decreases and has an impact on decreasing the current density. Second, the electrooxidation of formic acid over cathode can result in mixed potential and reduces the open-circuit potential. The numerical model shows that the main reason for the drop of the open-circuit potential from $0.78 \mathrm{~V}$ with $Q_{1}$ to $0.58 \mathrm{~V}$ with $Q_{3}$ are fuel crossover and the mixed potential at the cathode.

\subsection{Concentration distribution of oxygen}

The objective of using gas diffusion electrode as air-breathing cathode is to provide higher oxygen content at the cathode. In the numerical simulation, the cathode catalyst layer is considered as a boundary at the inner side of the channel where the electroreduction of oxygen takes place, Fig. 1. 
(a)

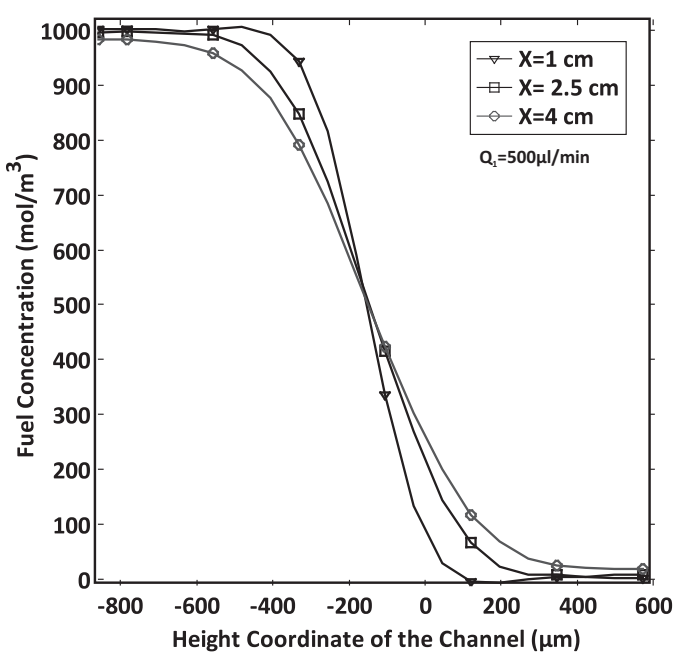

(b)



(C)

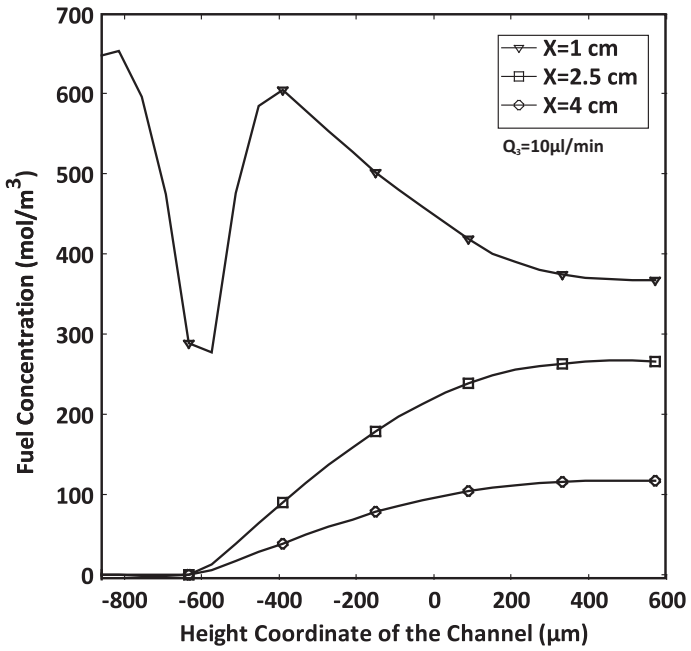

Figure 6. Concentration distribution of formic acid through the channel for three flow rates at three cross sections: (a) $Q 1=500 \mu \mathrm{L} / \mathrm{min}$; (b) $Q 2=100 \mu \mathrm{L} / \mathrm{min}$; (c) $Q 3=10 \mu \mathrm{L} / \mathrm{min}$. 
As Fig. 7 shows, oxygen can diffuse through the gas diffusion electrode to reach the catalyst layer. However the oxygen cations are formed over cathode catalyst layer and supposed to be fixed, oxygen can pass through the GDE and reach the liquid, and then diffuse into the aqueous streams in the channel. It is evident that the oxygen concentration through the gas diffusion electrode is almost constant.

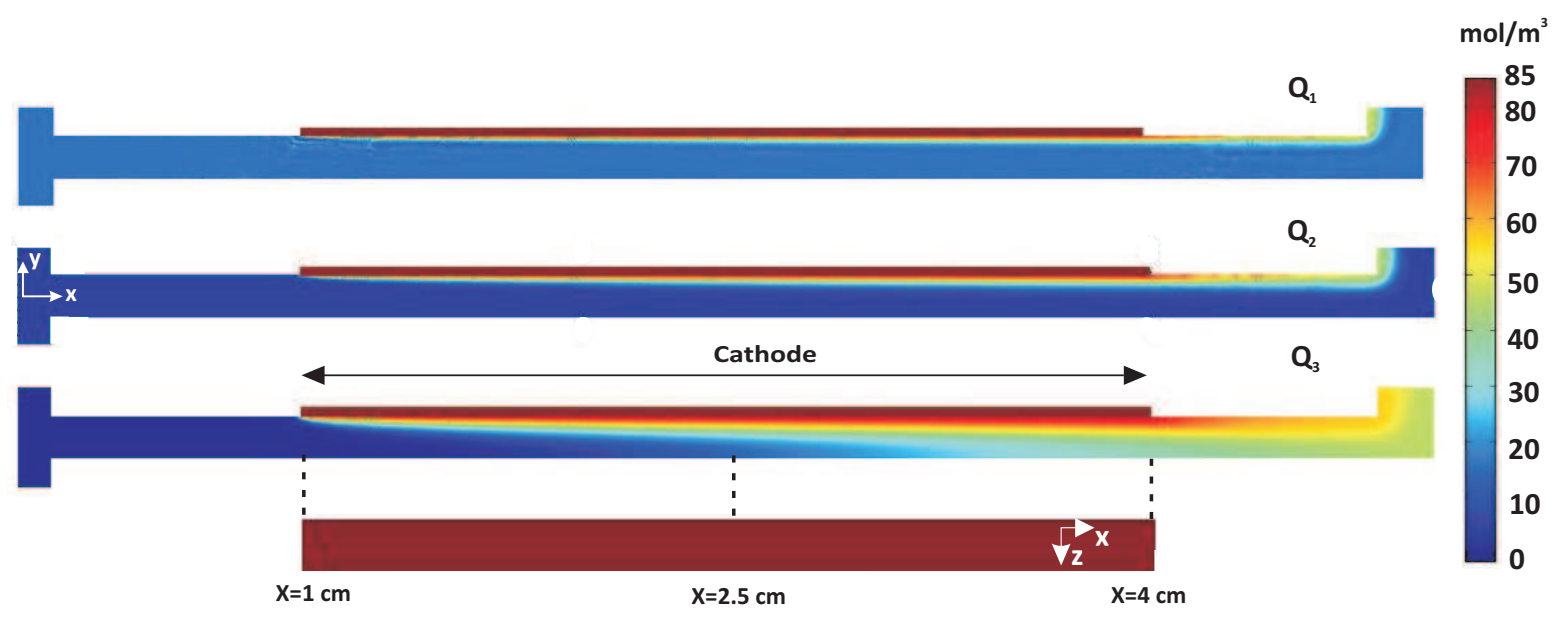

Figure 7. Concentration profiles of oxygen for three flow rates of $Q 1=500 \mu \mathrm{L} / \mathrm{min}$, $Q 2=100 \mu \mathrm{L} / \mathrm{min}$ and $Q 3=10 \mu \mathrm{L} / \mathrm{min}$. The T-shaped cross-section of the channel is located at the $x-y$ plane which cut through the center of the channel $(z=1 / 2 W)$ with a width of $W$.

Furthermore, Fig. 8 shows that unlike a LFFC with oxidant stream, the oxygen concentration at the vicinity of the cathode active area is almost constant. For all three flow rates, a sharp drop of oxygen concentration of the electrolyte rather than electrode is observable. This sharp drop is attributed to the difference in the higher diffusion coefficient of oxygen in porous media $\left(D_{\mathrm{O}_{2}(\mathrm{GDE})}=\frac{\varepsilon}{\tau} \times 2 \times 10^{-5} \mathrm{~m}^{2} / \mathrm{s}\right)$ and in water $\left(2 \times 10^{-9} \mathrm{~m}^{2} / \mathrm{s}\right)$.

The flow rate of the laminar streams inside the channel can affect the oxygen transport through the channel. At higher flow rates $Q_{1}$ and $Q_{2}$, the transported oxygen to the channel cannot diffuse to the anolyte stream and washed away with the electrolyte stream. At very low flow rate $\left(Q_{3}\right)$, oxygen has more residence time inside the channel to diffuse to the anolyte stream. The oxygen content over the catalyst layer of anode at the distance of $x=4 \mathrm{~cm}$ (the end of the anode) is around $35 \mathrm{~mol} / \mathrm{m}^{3}$. Diffusion of oxygen across the channel may result in oxygen crossover. The oxygen crossover to the anode may facilitate electro-reduction of oxygen and cause mixed potential resulting in lower open circuit potential. Since the voltage of anode is very low compared to the cathode potential, the effect of oxygen reduction on cell potential is minor.

\subsection{Fuel utilization and power density}

Fig. 9 shows the effect of raising flow rate from $10 \mu \mathrm{l} / \mathrm{min}$ to $500 \mu \mathrm{l} / \mathrm{min}$ on fuel utilization versus maximum power density under different flow rate conditions. The 


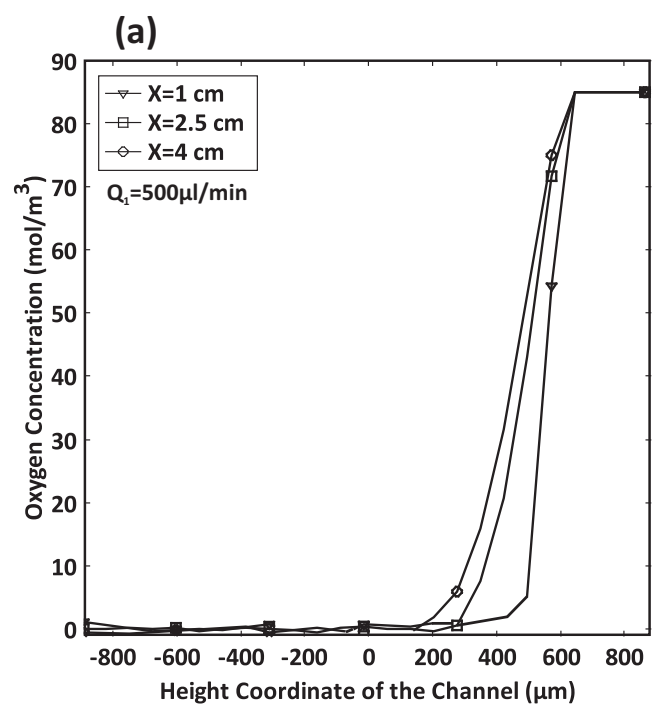

(b)



(c)

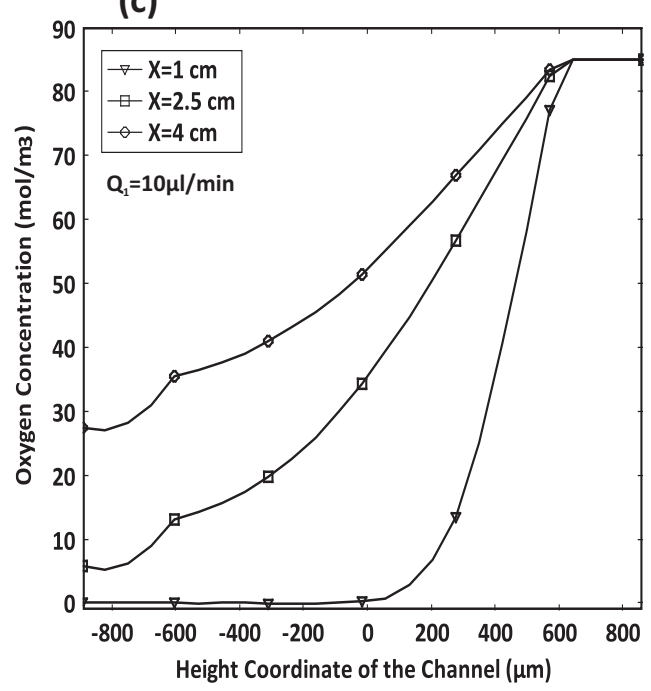

Figure 8. Concentration distribution of oxygen through the channel at three cross sections: (a) $Q 1=500 \mu \mathrm{L} / \mathrm{min}$; (b) $Q 2=100 \mu \mathrm{L} / \mathrm{min}$; (c) $Q 3=10 \mu \mathrm{L} / \mathrm{min}$. 
improvement of power density at higher flow rates can be associated with (a) the higher voltage generated due to the lower mixed potential at the cathode, and (b) the higher rate of electrochemical reaction to generate current because of the higher availability of reactants in the vicinity of the catalytic active sites. According to Equation (7), current generation over anode is highly dependent on the concentration of formic acid. Beside the low fuel concentration over the anode, the low open-circuit potential is another reason for the low power density of $Q_{3}$.

Fuel utilization is determined as [31]:

$$
\varepsilon_{\text {fuel }}=\frac{I}{n F Q_{\text {fuel }}}
$$

where $I$ is the current generated by the fuel cell, $Q_{\text {fuel }}$ is the fuel rate supplied to the cell in $\mathrm{mol} / \mathrm{sec}, n$ is the number of electrons transferred for every mol of the fuel. In the case of formic acid, $n=2, F=96,485 \mathrm{C} / \mathrm{mol}$ is the Faraday's constant. Fig. 9 clearly shows that a higher fuel flow rate leads to a high power density but a low fuel utilization.

At flow rates of 10, 100 and $500 \mu \mathrm{l} / \mathrm{min}$, the experimental fuel utilization of the cell at maximum experimental power density are $38.9 \%, 6.23 \%$ and $1.03 \%$, respectively. At the same flow rates, the numerical fuel utilization of the cell at the corresponding power density are $49.6 \%, 7.21 \%$ and $1.95 \%$, as depicted in Fig. 9. It is obvious that there is a good trend between experimental and numerical results, but a quantitative difference is observed for flow rate of $10 \mu \mathrm{l} / \mathrm{min}$. Concentration (mass transport) loss can decrease the cell potential at high current densities and especially for $10 \mu \mathrm{l} / \mathrm{min}$. Since the simulation does not include the impact of concentration losses on cell potential, error in calculating the cell potential could be introduced. Moreover, experimental uncertainities can be another source for this difference.

As Figs 5 and 6 illustrate, for flow rates of 100 and $500 \mu \mathrm{l} / \mathrm{min}$, the fuel concentration over anode is still high enough to produce more current, but only a part of the stream at the vicinity of the electrode is consumed. It seems that the core part of the flow including high concentration of fuel just passes through the channel without any contribution in producing current. High fuel utilization of the cell at $10 \mu \mathrm{l} / \mathrm{min}$ is contributed by the longer residential time in the channel leading to more fuel consumption.

As the flow rate of the laminar streams decreases almost two orders of magnitudes from $500 \mu \mathrm{l} / \mathrm{min}$ to $10 \mu \mathrm{l} / \mathrm{min}$, the corresponding maximum power density only drops from approximately $7.9 \mathrm{~mW} / \mathrm{cm}^{2}$ to $3.9 \mathrm{~mW} / \mathrm{cm}^{2}$. In this case, fuel utilization increases from $1.03 \%$ to $38.9 \%$. Unlike the conventional LFFCs, whose performances usually drop dramatically with decreasing fuel and oxidant flow rates [30, 2], the power output of a LFFC with an air-breathing cathode is less sensitive to flow rate compared to conventional LFFCs. An air-breathing LFFC with optimized flow architecture operating in very low flow rates seems to be a suitable power source for portable applications.

The anode is made of porous carbon paper which can present more active area rather than a non-porous and planar anode. The implementation of carbon paper in 


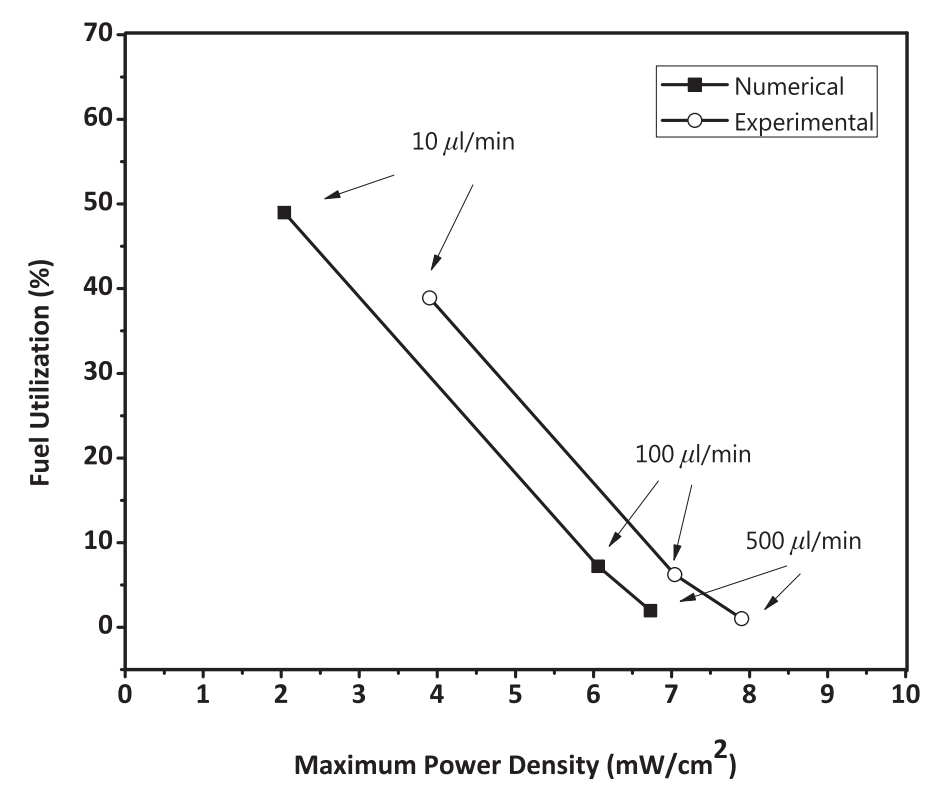

Figure 9. The experimental and simulated fuel utilization vs maximum power density.

the channel is supposed to replenish the depletion boundary layer. However numerical simulation of flow field within the channel with porous anode reveals that the velocity of liquid in porous media is almost zero, Fig. 9(a). In the other words, there is no effective advective mass transport through the porous anode to provide fresh reactants to the active sites.

Using the concept of "flow-though porous electrode" [30] to design anode can promote the replenishment of the depletion layer by enhanced advective transport to develop the fuel utilization. Also, a new configuration of channel which can facilitate the mass transfer from the core part of the fuel stream to the active area of the anode, without disturbing the interface, can be considered as a strategy to develop the fuel utilization at high flow rates.

Figure 11 depicts the long-term stability of the current generated by the airbreathing fuel cell evaluated by a potentiostatic test at $0.25 \mathrm{~V}$ cell voltage and $100 \mu \mathrm{l} / \mathrm{min}$. After a brief transient period, the cell current density is stable over the 2 hours of experiment with an average value of $7.92 \mathrm{~mA} / \mathrm{cm}^{2}$. The fluctuations could be caused by $\mathrm{CO}_{2}$ bubbles occupying active sites in the porous anode. Since $\mathrm{CO}_{2}$ bubbles can be dissolved in the aqueous media, the occupied micro pores with carbon dioxide in the electrode can be refilled with fuel again. This phenomena of $\mathrm{CO}_{2}$ generation and replenishment could cause fluctuations in the generated current.

\section{Conclusions}

This paper reports on the fabrication, characterization, and simulation of an airbreathing LFFC running on formic acid with integrated porous planar electrode as anode inside the channel. The fuel cell was fabricated using laser micromachining and 

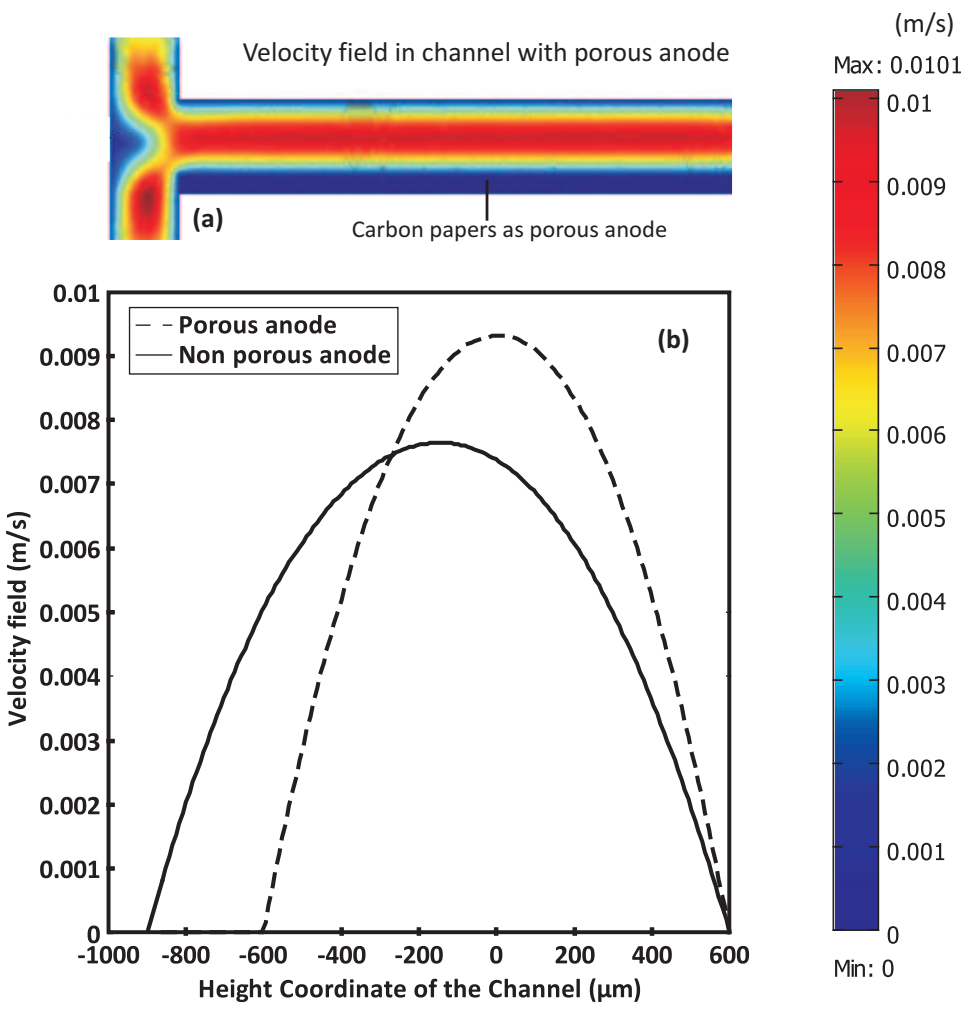

Figure 10. Flow field simulation: (a) simulated velocity field in channel with porous anode; (b) Velocity profile across the channel for porous and non porous anode at a flow rate of $500 \mu \mathrm{l} / \mathrm{min}$.

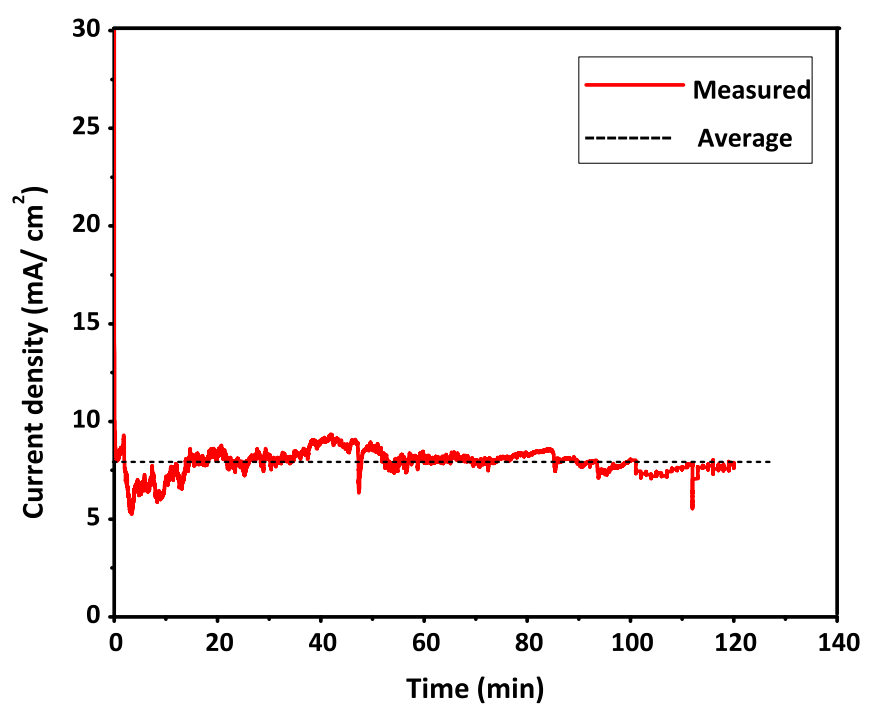

Figure 11. Steady-state chronoamperometric measurement at $0.25 \mathrm{~V}$ cell potential and $100 \mu \mathrm{l} / \mathrm{min}$ flow rate. 
characterized at three different flow rates. The experimental results demonstrate that at high flow rates the open-circuit voltage is higher, but low fuel utilization is achieved imposing some requirements for fuel recirculation for real applications. High rate of fuel utilization at high cell potentials are desirable to achieve high overall energy conversion efficiency. As a general design consideration, a compromise between high fuel utilization rate and high mass-limitation loss needs to be met. Exploiting a flow-through porous anode can provide advective mass transport to replenish the depletion layer over anode to develop fuel utilization and current density. Operation in low flow rates results in high fuel utilization. Optimizations of air-breathing MFFC for operation in low flow rates to achieve high fuel utilization, can eliminate the requirements for fuel utilization. In this case, an air-breathing LFFC has more possiblities as a power source for micro-power applications.

\section{References}

[1] Ferrigno R, Stroock AD, Clark TD, Mayer M, Whitesides GM 2002 Membraneless vanadium redox fuel cell using laminar flow Journal of the American Chemical Society 124 12930-12931.

[2] Li A, Chan SH, Nguyen NT 2007 A laser-micromachined polymeric membraneless fuel cell Journal of Micromechanics and Microengineering 17 1107-1113.

[3] Kjeang E, Brolo AG, Harrington DA, Djilali N and Sinton D 2006 Hydrogen peroxide as an oxidant for microfluidic fuel cells Journal of The Electrochemical Society 154 B1220-B1226.

[4] Kjeang E, McKechnie J, Sinton D and Djilali N 2007 Planar and three-dimensional microfluidic fuel cell architectures based on graphite rod electrodes Journal of Power Sources 168 379-390.

[5] Jayashree RS, Gancs L, Choban ER, Primak A, Natarajan D, Markoski LJ and Kenis PJA 2005 Air-breathing laminar flow-based microfluidic fuel cell Journal of the American Chemical Society 127 16758-16759.

[6] Jayashree RS, Egas D, Spendelow JS, Natarajan D, Markoski LJ and Kenis PJA 2006 Air-breathing laminar flow-based direct methanol fuel cell with alkaline electrolyte Electrochemical and SolidState Letters 9 A252-A256.

[7] Whipple DT, Jayashreea RS, Egas D, Alonso-Vante N and Kenis PJA 2009 Ruthenium clusterlike chalcogenide as a methanol tolerant cathode catalyst in air-breathing laminar flow fuel cells Electrochimica Acta 54 4384-4388.

[8] Hollinger, AS, Maloney, RJ, Jayashree, RS, Natarajan, D, Markoski, LJ and Kenis PJA 2010 Nanoporous separator and low fuel concentration to minimize crossover in direct methanol laminar flow fuel cells Journal of Power Sources 195 3523-3528.

[9] Tominaka S, Ohta S, Obata H, Momma T and Osaka T 2008 On-chip fuel cell: micro direct methanol fuel cell of an air-breathing, membraneless, and monolithic design Journal of the American Chemical Society 130 10456-10457.

[10] Jayashree RS, Yoon SK, Brushett FR, Lopez-Montesinos PO, Natarajan Dilip, Markoski LJ, Kenis PJA 2010 On the performance of membraneless laminar flow-based fuel cells Journal of Power Sources 195 3569-3578

[11] Bazylak A, Sinton D and Djilali N 2005 Improved fuel utilization in microfluidic fuel cells: A computational study Journal of Power Sources 143 57-66.

[12] Chen W and Chen F 2006 Theoretical approaches to studying the single and simultaneous reactions in laminar flow-based membraneless fuel cells Journal of Power Sources 162 1137-1146.

[13] Chang MH, Chen F and Fang NS 2006 Analysis of membraneless fuel cell using laminar flow in a $Y$-shaped microchannel Journal of Power Sources 159 810-816. 
[14] Chen F, Chang MH and Hsu CW 2007 Analysis of membraneless microfuel cell using decomposition of hydrogen peroxide in a Y-shaped microchannel Electrochimica Acta 52 7270-7277.

[15] Lee J, Lim KG, Palmore G, Tayhas R and Tripathi A 2007 Optimization of microfluidic fuel cells using transport principles Analytical Chemistry 79 7301-7307.

[16] Xu JB, Zhao TS and Liang ZX 2008 Carbon supported platinum-gold alloy catalyst for direct formic acid fuel cells Journal of Power Sources 185 857-861.

[17] Uhm S, Lee HJ, Lee J 2009 Understanding underlying processes in formic acid fuel cells Phys. Chem. Chem. Phys. 11 9326-9336.

[18] Park GG, Sohn YJ, Yang TH, Yoon YG, Lee WY, Kim CS 2004 Effect of PTFE contents in the gas diffusion media on the performance of PEMFC Journal of Power Sources 131 182-187.

[19] Song C, and Zhang J 2008 Electrocatalytic Oxygen Reduction Reaction, in PEM Fuel Cell Electrocatalysts and Catalyst Layers: Fundamentals and Applications Zhang J, Editor, Springer 89-129.

[20] Yeom J, Jayashree RS, Rastogi C, Shannon MA, Kenis PJA 2006 Passive direct formic acid microfabricated fuel cells Journal of Power Sources 160 1058-1064.

[21] Rice C, Ha S, Masel RI, Waszczuk P, Wieckowski A, Barnard T 2002 Direct formic acid fuel cells Journal of Power Sources 111 83-89.

[22] Nield DA and Bejan A 2006 Convection in porous media Springer.

[23] O'Hayre R, Fabian T, Litster S, Prinz FB, Santiago JG 2007 Engineering model of a passive planar air breathing fuel cell cathode Journal of Power Sources 167 118-129.

[24] Chen R, and Zhao TS 2005 Mathematical modeling of a passive-feed DMFC with heat transfer effect Journal of Power Sources 152 122-130.

[25] Chen F, Chang MH, Lin MK, 2008 Analysis of membraneless formic acid microfuel cell using a planar microchannel Electrochimica Acta 52 2506-2514.

[26] Zhang LJ, Wang ZY, and Xia DG 2006 Bimetallic PtPb for formic acid electro-oxidation Journal of Alloys and Compounds 426 268-271.

[27] Feser JP, Prasad AK, Advani SG 2006 Experimental characterization of in-plane permeability of gas diffusion layers Journal of Power Sources 162 1226-1231.

[28] Chan SH, Khor K.A, Xia ZT 2001 A complete polarization model of a solid oxide fuel cell and its sensitivity to the change of cell component thickness Journal of Power Sources 93 130-140.

[29] Mench MM 2008 Fuel Cell Engines John Wiley and Sons.

[30] Kjeang E, Michel R, Harrington DA, Djilali N and Sinton D 2008 A microfluidic fuel cell with flow-through porous electrodes Journal of the American Chemical Society 130 4000-4006.

[31] O'Hayre RP, Cha SW, Colella W and Prinz F, 2006 Fuel cell fundamentals, John Wiley and Sons. 